\title{
Determining Fatigue Threshold according to Burned Calories for Energy Management in Pedal-Assist Electric Bike Riding
}

\author{
Sohrab Ebnealipour, Masoud masih Tehrani* and Hossein Nazemian \\ Vehicle System Dynamics Research Laboratory, School of Automotive Engineering, Iran University of Science and \\ Technology, Tehran Iran
}

*Corresponding author: Masoud masih Tehrani, Vehicle System Dynamics Research Laboratory, School of Automotive Engineering, Iran University of Science and Technology, Tehran Iran

\begin{tabular}{|c|c|}
\hline ARTICLE INFO & ABSTRACT \\
\hline Received: 幽 April 29, 2020 & \multirow{4}{*}{$\begin{array}{l}\text { The Pedal assist electric bike consists of two electric and human propulsions. One } \\
\text { of the interesting ideas that can be developed on electric bicycles is equipping the bike } \\
\text { with a switch controller in order to change the power source between human and } \\
\text { electric power sources. In the process of doing this research, it is necessary to recognize } \\
\text { the driving force of humans, so it is possible to make a balance between two energy } \\
\text { sources. In the first part of this paper, a model for calorie burning is designed during } \\
\text { cycling, according to the relationship between heart rate and physical characteristics } \\
\text { such as weight, age, and gender, then the effect of weight and age on the amount of } \\
\text { burned calories is investigated. For the validity of the relation between heart rate and } \\
\text { calorie burning, it is compared with online software. After designing the model, by } \\
\text { performing metabolic tests, the maximum amount of calorie that a driver will not get } \\
\text { tired for the age range from } 25 \text { to } 35 \text { years and weight } 90 \mathrm{Kg} \text { has been obtained, which } \\
\text { is } 180 \mathrm{Kcal} \text {. For ages from } 15 \text { to } 25 \text { and from } 35 \text { to } 45 \text { years and weight } 90 \mathrm{~kg} \text {, these } \\
\text { values are equal to } 186 \mathrm{Kcal} \text { and } 175 \mathrm{Kcal} \text {, respectively. Also, with using online software } \\
\text { and curve fitting for other age and weight ranges, the relationships have been created } \\
\text { to estimate maximum burned calorie for wider physical body situation range in the } \\
\text { condition that driver will not get tired. }\end{array}$} \\
\hline Published: May 07, 2020 & \\
\hline $\begin{array}{l}\text { Citation: Sohrab Ebnealipour, Masoud } \\
\text { masih Tehrani, Hossein Nazemian. Deter- } \\
\text { mining Fatigue Threshold according to } \\
\text { Burned Calories for Energy Management } \\
\text { in Pedal-Assist Electric Bike Riding. Bi- } \\
\text { omed J Sci \& Tech Res 27(3)-2020. BJSTR. } \\
\text { MS.ID.004510. }\end{array}$ & \\
\hline $\begin{array}{l}\text { Keywords: Electric Bicycle; Human Power; } \\
\text { Body Fatigue; Calorie Burning; Metabolic } \\
\text { Activity }\end{array}$ & \\
\hline
\end{tabular}

\section{Introduction}

The pedal-assist electric bike is interesting equipment because of using these two power sources $[1,2]$. Predicting the performance of an electric bike requires recognizing both of these driving forces. Activities have been carried out on the electric propulsion force. And due to the structure of electric propulsion, its performance is more predictable than human propulsion. Therefore, in order to make this energy management more applicable, human driving propulsion must be well known [3]. Jessica E Bourne, et al. [4] studied on health improvements by using e-bikes [4]. The driver's tiredness influences power generation from the human power source. Therefore, the driver might not be able to reach the destination earlier than a specified time. So, the major part of this study is covered by the driver's tiredness issue. The researchers such as Alex OW Natera, et al, [5-7] studied environmental factors that affect human fatigue while driving a bicycle [5-8]. Moreover, there are some fac tors related to human physiques that have an impact on human fatigue also $[9,10]$. Determining the fatigue threshold for the human is so important to discuss that has been done by Didace Ndahimana, et al. [11]. Considering cooling down and warming up time for the driver and following some basic sport instructions can protect the driver from damage and extreme fatigue [12]. Calculating the burned calories is a way to determine the driver's fatigue while exercising. The calculation process is performed with different means [13].

There are different methods to calculate burned calories and determining the driver's tiredness status. Doubly labeled water (DLW) method is an accurate method but it is costly. Because it needs high advanced devices, and, specialties' attendance is required. A calorimeter is a direct way to calculate consumed energy but it is an expensive method. There is an indirect method that is 
accurate enough. This method obtains the consumed energy and metabolic information of the driver in different environmental conditions. This method is alike DLW because specialties' attendance is required also. Due to this reason, it becomes expensive. The acceleration measurement is a rough method but it is inexpensive. Monitoring the heart rate is a simple measurement method for calculating human energy consumption [11]. According to the studies, it is necessary to have mathematical relationships that can predict the performance of human driving forces. Monitoring the heart rate is not an accurate method for a low level of mobility and exercise. In this paper, due to the energy consumption that is calculated in high active performance, this method is practical. Mi Band 3 is used as a heart rate sensor. By performing experimental tests and using online software, the relationships will be created to relate the heart rate and burned calorie.

\section{Metabolic Activity}

The corresponding e-bike is equipped with two types of power sources such as electric and human power. The electric power source system consists of battery, electric motor, and, controller. In this Section, the purpose is to investigate factors on human power generation. The human power generation has tight relation with

Table 1: Muscle energy technique (MET) evaluation.

\begin{tabular}{|c|c|c|}
\hline Description & Speed Range & MET \\
\hline Leisure, quiet, low effort & From 12.87 to 19.45 & 8 \\
\hline Fun race, medium effort & From 19.45 to 22.37 & 10 \\
\hline Race, fast, fast effort & From 22.37 to 25.59 & 12 \\
\hline Race very fast & From 25.59 to 32.03 & More than 32.03 \\
\hline
\end{tabular}

Driver's Physical Characteristics Impacts on Burning Calorie

In continue, there are some charts and graphs to illustrate the influences of the driver's physical traits on the calorie burning. Table 2 describes the burned calorie amount in different weights. The tests are done with Keisan online calculator software. The target driver in this software is a 20-year-old male driver rides a bicycle with $11 \mathrm{mph}$ speed in 20 minutes with having different weights as they are shown in Table 2. The results are obtained and shown also. metabolic parameters such as the driver's heart rate, maximum oxygen consumed volume, weight, gender, and, age. One important issue should be discussed is to determine the fatigue threshold. People have different fatigue threshold, so, there are some proposed means to measure the estimation of this value for any person. In this paper, the driver's fatigue level is determined by burned calories in a certain sport activity. Equation (1) expresses a relation between driver's physics such as heart rate hr in beat per minute (bpm), gender, age a considering year, weight w in kilogram unit, and burned calories Cal in kilocalorie unit [14].

Cal $=\frac{t}{4.184}\left\{\begin{array}{l}-55.0969+0.6309 h r+0.1988 w+0.2017 a \\ -20.4022+0.4472 h r-0.1263 w+0.074 a\end{array}\right.$ for women drivers

There is a linear relation between passed time $t$ and burned calorie rate. As was discussed in Introduction Section, an online software named "Keisan online calculator" is used to calculate the burned calories. This software works based on Equation (2) to obtain burned calories.

$$
E x=0.0175 \times M E T \times w
$$

Equation (2) expresses the burned calories $E x$ in kilocalories per minute. MET is muscle energy technique that is evaluated according to Table 1 is given further $[13,14]$.

Table 2: Driver's weight influence on burning calorie.

\begin{tabular}{|c|c|c|c|c|}
\hline Weight & Mileage & Average Heart Rate & Calories Burned (Eq 2) & Calories Burned (Eq 1) \\
\hline $70 \mathrm{~kg}$ & $5.87 \mathrm{~km}$ & $114 \mathrm{bpm}$ & $166 \mathrm{kcal}$ & $166.23 \mathrm{kcal}$ \\
\hline $80 \mathrm{~kg}$ & $5.87 \mathrm{~km}$ & $115 \mathrm{bpm}$ & $178 \mathrm{kcal}$ & $178.750 \mathrm{kcal}$ \\
\hline $90 \mathrm{~kg}$ & $5.87 \mathrm{~km}$ & $116 \mathrm{bpm}$ & $191 \mathrm{kcal}$ & $191.269 \mathrm{kcal}$ \\
\hline $100 \mathrm{~kg}$ & $5.87 \mathrm{~km}$ & $117 \mathrm{bpm}$ & $203 \mathrm{kcal}$ & $203.788 \mathrm{kcal}$ \\
\hline $110 \mathrm{~kg}$ & $5.87 \mathrm{~km}$ & $118 \mathrm{bpm}$ & $216 \mathrm{kcal}$ & $216.306 \mathrm{kcal}$ \\
\hline
\end{tabular}

\section{Experimental Tests}

An examination has been done on four people to ride a bicycle
Table 2 shows the validity of Equations (1) and (2). Because they are approximately equal. Figure 1 shows this equality. It is comprehended in Figure 1 that there is a linear relationship between weight and burning calories. To investigate more factors, it is important to consider age variations. Table 3 shows the burned calories are obtained with Keisan online calculator software. Table 3 shows the wide range of ages to cover all someone's lifetime. Like Figure 1, the age influence diagram is given in Figure 2. This diagram proves the validity of these two equations (1), (2). It is inferred that old people have slow calorie burning in comparison with youths.

around the soccer field in Iran university of science and technology. The drivers were supposed to continue riding until they feel tired. 
These people aged from 25 to 35 years old and weighed from 85 to 95Kg. Table 4 shows these four people's characteristics and results. The purpose of these tests is to determine the tiredness threshold in young students. The students rode the bicycle to reach this threshold then they stop. According to Figure 3, At the beginning of the test, the heart rate gradually increases at the warm-up level. After a while, the heart rate reaches its peak value. In this situation, the driver is close to the fatigue level. By feeling tired, the driver reduces the speed to stop the riding afterward. In recovery duration, the heart rate reduces due to driver low activity. As it is evident in Figure 3, the students have different recovery start time. Figure 4 shows the corresponding calorie burning to the driver's heart rate. The burning calorie in these tests is obtained by Mi Band 3 heart rate sensor installed on the driver's wrist. The diagrams in Figure 4 are monotonically increasing functions. Because the calorie burning is accumulative. Table 5 shows the other eight peoples test and their results.

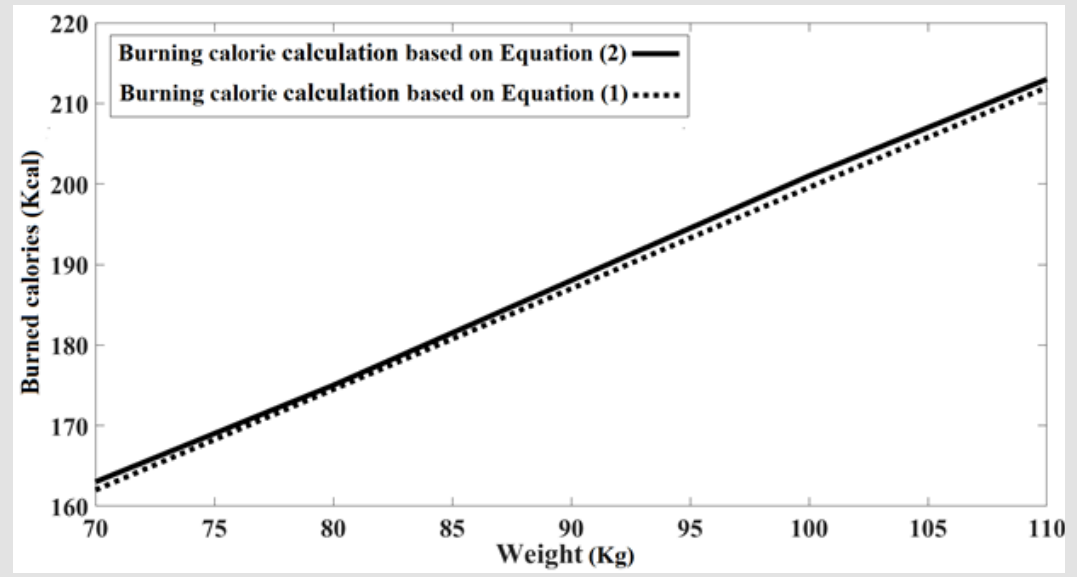

Figure 1: The validity of two equations in weight influences.

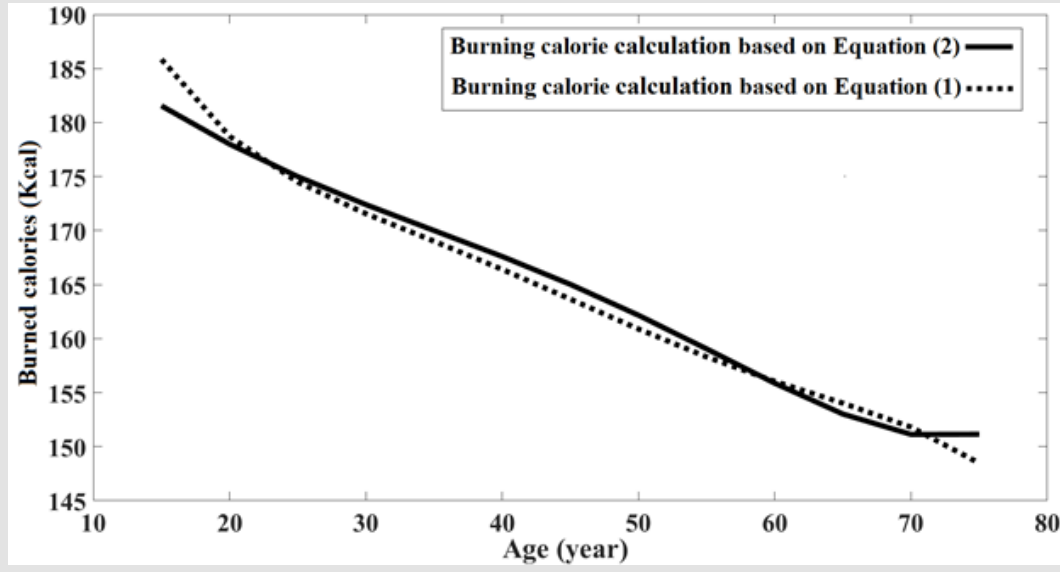

Figure 2: The validity of two equations in age influences.

Table 3: Driver's weight influence on burning calorie.

\begin{tabular}{|c|c|c|c|c|}
\hline Age & mileage & Average Heart Rate & Calories Burned (Eq 2) & Calories Burned (Eq 1) \\
\hline 20 & $5.87 \mathrm{~km}$ & $115 \mathrm{pbm}$ & $178 \mathrm{kcal}$ & $178.750 \mathrm{kcal}$ \\
\hline 30 & $5.87 \mathrm{~km}$ & $112 \mathrm{pbm}$ & $175 \mathrm{kcal}$ & $174.5 \mathrm{kcal}$ \\
\hline 40 & $5.87 \mathrm{~km}$ & $107 \mathrm{pbm}$ & $170 \mathrm{kcal}$ & $169 \mathrm{kcal}$ \\
\hline 50 & $5.87 \mathrm{~km}$ & $102 \mathrm{pbm}$ & $165 \mathrm{kcal}$ & $163.3 \mathrm{kcal}$ \\
\hline 60 & $5.87 \mathrm{~km}$ & $97 \mathrm{pbm}$ & $159 \mathrm{kcal}$ & $158.2 \mathrm{kcal}$ \\
\hline 70 & $5.87 \mathrm{~km}$ & $90 \mathrm{pbm}$ & $151 \mathrm{kcal}$ & $151.6 \mathrm{kcal}$ \\
\hline
\end{tabular}

\section{Driver's Fatigue}

To consider the limitation in optimization section, it is required to determine the tiredness level of each driver in burning calories according to his or her physical traits. The experimental tests show 
that in a certain range of age and weight, the burned calories are about $180 \mathrm{Kcal}$ in the condition that the driver reaches the fatigue threshold. Equation (3) obtains the tiredness fatigue level for a wide range of age between 15 to 75 years old. The factors $a_{1}, a_{2}$, $a_{3}$, and, ${ }^{a_{4}}$ are evaluated by Table 3 according to the driver's mass range. The tiredness level is determined in burned calories (Kcal) to limit the maximum allowable calorie burning before the driver becomes tired. These factors are obtained by poly fitting among the data are extracted from online software. Equation (3) and Table 6 cover age and weight variables to find the tiredness level.

$$
T=a_{1} \times w^{3}+a_{2} \times w^{2}+a_{3} \times w+a_{4}
$$
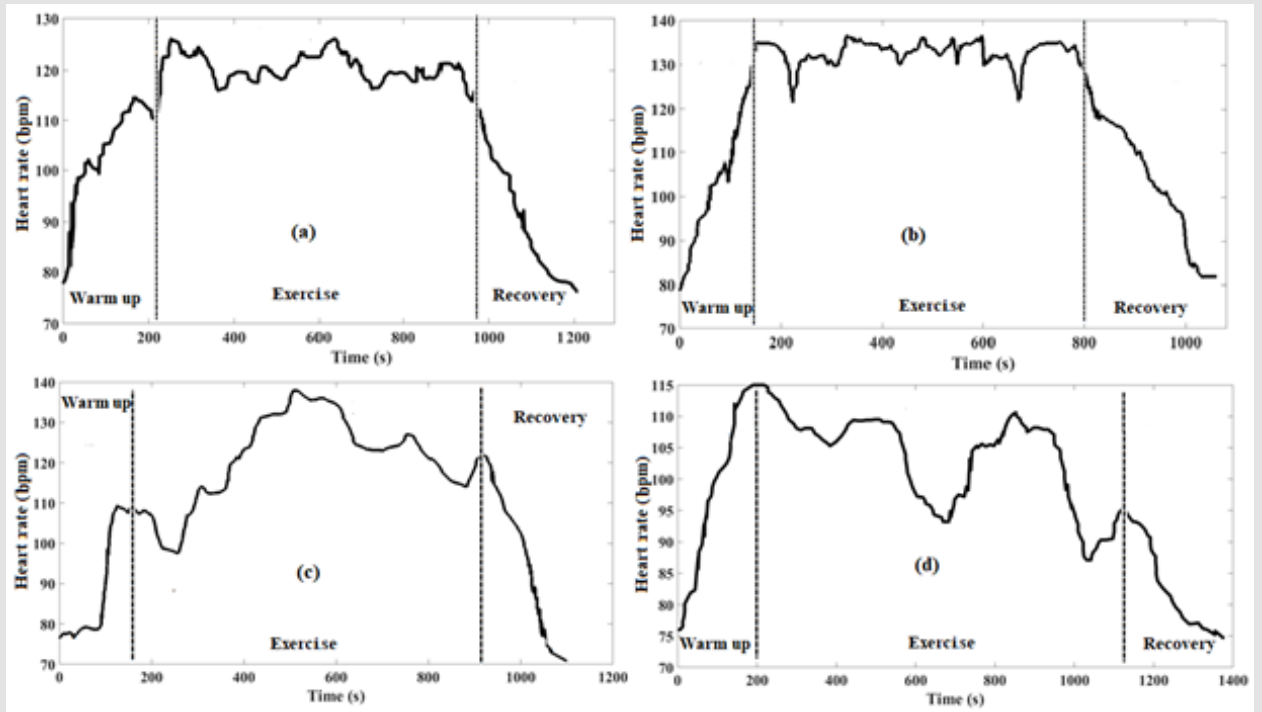

Figure 3: Driver's heart rate.

(a) Test number one.

(b) Test number two.

(c) Test number three.

(d) Test number four.

Table 4: Driver's physical traits in the experiment test.

\begin{tabular}{|c|c|c|c|}
\hline \multicolumn{2}{|c|}{ Test Number One } & \multicolumn{2}{c|}{ Test Number Two } \\
\hline Age & 25 years old & Height & 19 years old \\
\hline Height & $179 \mathrm{~cm}$ & Weight & $94 \mathrm{~kg}$ \\
\hline Weight & $87 \mathrm{~kg}$ & Average speed & 14.23 \\
\hline Average speed & $13.41 \mathrm{~km} / \mathrm{h}$ & Mileage & $3650 \mathrm{~m}$ \\
\hline Mileage & $4900 \mathrm{~m}$ & Test time & $1035 \mathrm{~s}$ \\
\hline Test time & $1207 \mathrm{~s}$ & average Heart rate & $125 \mathrm{bpm}$ \\
\hline average Heart rate & $114 \mathrm{bpm}$ & Calories burned & $192 \mathrm{kcal}$ \\
\hline Calories burned & $183 \mathrm{kcal}$ & Temperature & $19 \mathrm{c}$ \\
\hline Temperature & $23 \mathrm{c}$ & & $26 \mathrm{years}$ old \\
\hline Test Number Three & & Age & $179 \mathrm{~cm}$ \\
\hline Age & 25 years old & Height & $84 \mathrm{~kg}$ \\
\hline Height & $183 \mathrm{~cm}$ & Weight & 15.05 \\
\hline Weight & $89 \mathrm{~kg}$ & Average speed & $5800 \mathrm{~m}$ \\
\hline Average speed & $15.19 \mathrm{~km} / \mathrm{h}$ & Mileage & $1378 \mathrm{~s}$ \\
\hline Mileage & $5000 \mathrm{~m}$ & Test time & $114 \mathrm{bpm}$ \\
\hline Test time & $1070 \mathrm{~s}$ & average Heart rate & $170 \mathrm{kcal}$ \\
\hline average Heart rate & $105 \mathrm{bpm}$ & Calories burned & $20 \mathrm{c}$ \\
\hline Calories burned & $173 \mathrm{kcal}$ & temperature & \\
\hline Temperature & $15 \mathrm{c}$ & & \\
\hline
\end{tabular}



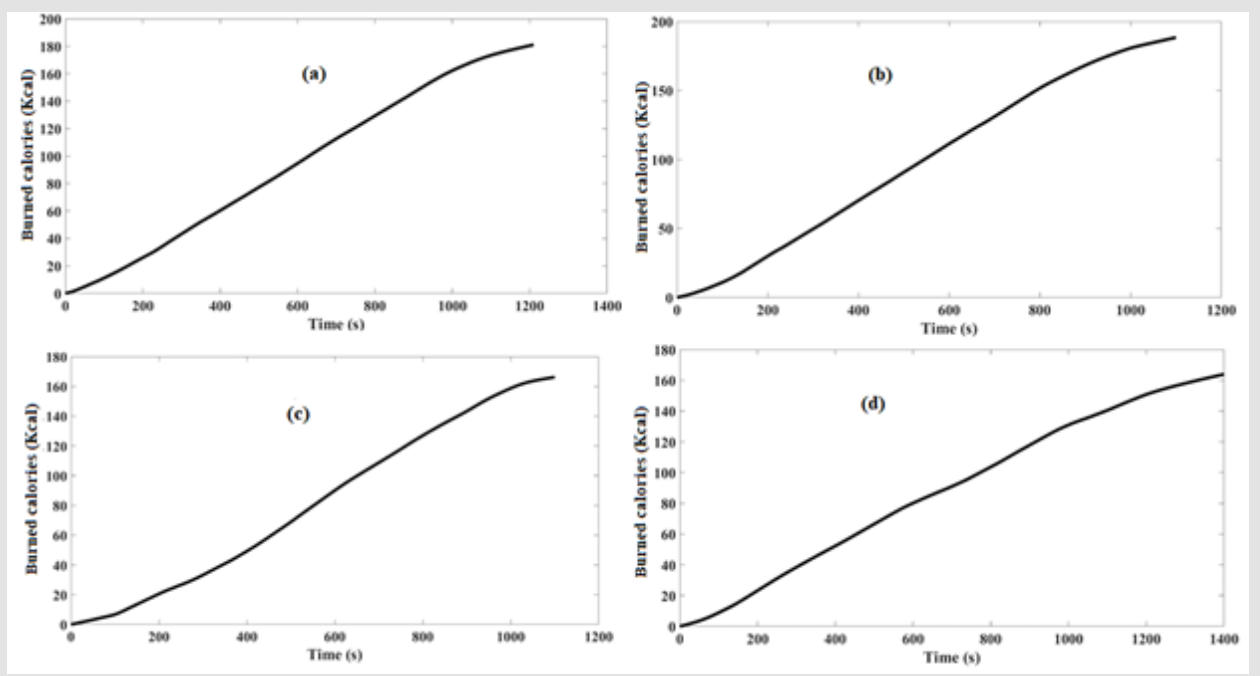

Figure 4: Calorie burning experimental tests.

(a) Test number one.

(b) Test number two.

(c) Test number three.

(d) Test number four.

Table 5: The other Driver's physical traits in the experiment test.

\begin{tabular}{|c|c|c|c|c|c|c|c|}
\hline Test Number & Age & Weight & Test Time & Average Speed & Average Heart Rate & Burned Calories & Mileage Distance \\
\hline 1 & 25 & $77(\mathrm{~kg})$ & $1250(\mathrm{~s})$ & $15.2(\mathrm{~km} / \mathrm{h})$ & $107(\mathrm{bpm})$ & $162 \mathrm{kcal}$ & $5277(\mathrm{~m})$ \\
\hline 2 & 26 & $84(\mathrm{~kg})$ & $1165(\mathrm{~s})$ & $14.89(\mathrm{~km} / \mathrm{h})$ & $112(\mathrm{bpm})$ & $169 \mathrm{kcal}$ & $4810(\mathrm{~m})$ \\
\hline 3 & 26 & $98(\mathrm{~kg})$ & $1134(\mathrm{~s})$ & $15.3(\mathrm{~km} / \mathrm{h})$ & $118(\mathrm{bpm})$ & $185 \mathrm{kcal}$ & $4819(\mathrm{~m})$ \\
\hline 4 & 27 & $107(\mathrm{~kg})$ & $1278(\mathrm{~s})$ & $14.1(\mathrm{~km} / \mathrm{h})$ & $109(\mathrm{bpm})$ & $197 \mathrm{kcal}$ & $5055(\mathrm{~m})$ \\
\hline 5 & 22 & $69(\mathrm{~kg})$ & $1340(\mathrm{~s})$ & $15.1(\mathrm{~km} / \mathrm{h})$ & $107(\mathrm{bpm})$ & $157 \mathrm{kcal}$ & $5612(\mathrm{~m})$ \\
\hline 6 & 18 & $74(\mathrm{~kg})$ & $1250(\mathrm{~s})$ & $15.4(\mathrm{~km} / \mathrm{h})$ & $112(\mathrm{bpm})$ & $165 \mathrm{kcal}$ & $5347(\mathrm{~m})$ \\
\hline 7 & 38 & $80(\mathrm{~kg})$ & $1120(\mathrm{~s})$ & $13.8(\mathrm{~km} / \mathrm{h})$ & $109(\mathrm{bpm})$ & $162(\mathrm{kcal})$ & $4293(\mathrm{~m})$ \\
\hline 8 & 43 & $84(\mathrm{~kg})$ & $1205(\mathrm{~s})$ & $14.56(\mathrm{~km} / \mathrm{h})$ & $105(\mathrm{bpm})$ & $169(\mathrm{kcal})$ & $4875(\mathrm{~m})$ \\
\hline
\end{tabular}

Table 6: Equation (3) factors evaluation.

\begin{tabular}{|c|c|c|c|c|}
\hline Age Range & $\boldsymbol{a}_{1}$ & $\boldsymbol{a}_{2}$ & $\boldsymbol{a}_{3}$ & $\boldsymbol{a}_{4}$ \\
\hline From 15 to 25 & -2.037 & 0.005926 & 0.678 & 90.83 \\
\hline From 25 to 35 & 1.046 & -0.03657 & 5.415 & -87.42 \\
\hline From 35 to 45 & 1.204 & -0.00343 & 1.523 & 56.92 \\
\hline From 45 to 55 & 1.204 & -0.00343 & 1.523 & 51.92 \\
\hline From 55 to 65 & 2.346 & -0.07019 & 7.731 & -124.4 \\
\hline From 65 to 75 & 4.63 & -0.00157 & 1.375 & 45.58 \\
\hline
\end{tabular}

\section{Conclusion}

It is required to understand the performance of both human and electric power source for energy management in a pedal-assist electric bike. For recognizing the human power source, a test on students have been performed to determine the fatigue threshold for different physical body situation. Equation (3) is the fatigue threshold determiner. By poly fitting among the data that are obtained by experimental tests and online software, this equation is extended for other range of age and weight. This equation evaluates the maximum burned calorie in the condition that the cyclist will not get tired and this evaluation depends on the driver's age and weight. This is very useful to design a controller to switch between these two power sources. In other words, this is a basic step for making smart this knid of bicycles. After importing the route, the processor can make a plan for switching in a case that the driver could pass the route without getting tired and the battery level stays in a high position as much as possible.

\section{References}

1. S Berntsen, L Malnes, A Langåker, E Bere (2017) Physical activity when riding an electric assisted bicycle. Int J Behav Nutr Phys Act 14(1): 55. 
2. P Spagnol, G Alli, C Spelta, P Lisanti, F Todeschini, et al. (2012) A full hybrid electric bike: How to increase human efficiency. 2012 Am Control Conf 6314871: 2761-2766.

3. B Sperlich, C Zinner, K Hebert Losier, DP Born, H C Holmberg (2012) Biomechanical, cardiorespiratory, metabolic and perceived responses to electrically assisted cycling. Eur J Appl Physiol 112(12): 4015-4025.

4. JE Bourne, Sarah Sauchelli, Rachel Perry, Angie Page, Sam Leary, et al (2018) Health benefits of electrically-assisted cycling: A systematic review 11 Medical and Health Sciences 1117 Public Health and Health Services. Int J Behav Nutr Phys Act 15(1):116.

5. AOW Natera, J Jennings, AJ Oakley, TW Jones (2019) Influence of environmental conditions on performance and heart rate responses to the 30-15 incremental fitness test in rugby union athletes. J Strength Cond Res 33(2): 486-491.

6. RAA E Oliveira, HVR Spineli Silva, F R De Oliveira (2017) Acclimated young and adult athletes present a psychophysiological response and exercise tolerance that is similar under cool environmental conditions and under impeded dehydration during long distance running. J Phys Educ Sport 17(1): 371-377.

7. Annika Hackemann, Krusemark Helge (2019) Sports Under Extreme Conditions. Sport Med Physician. pp. 481-487.

ISSN: 2574-1241

DOI: $10.26717 /$ BJSTR.2020.27.004510

Masoud masih Tehrani. Biomed J Sci \& Tech Res

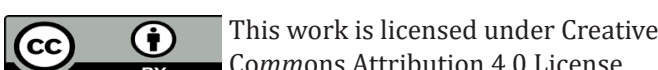

Submission Link: https://biomedres.us/submit-manuscript.php
8. P Schantz (2017) Distance, duration, and velocity in cycle commuting: Analyses of relations and determinants of velocity. Int J Environ Res Public Health 14(10): 1166

9. SL Halson (2014) Monitoring Training Load to Understand Fatigue in Athletes Shona L Halson Ó. Sport Med 44(2): 139-147.

10. JBF Vercruyssen, R Suriano, D Bishop, C Hausswirth (2005) Cadence selection affects metabolic responses during cycling and subsequent running time to fatigue. Br J Sports Med 39(5): 267-272.

11. EKK, Didace Ndahimana (2017) Measurement Methods for Physical Activity and Energy Expenditure: a Review. Clin Nutr Res 6(2): 68-80.

12. NAR, MS Koehle (2019) Optimizing recovery to support multi-evening cycling competition performance. Eur J Sport Sci 19(6): 811-823.

13. M De Almeida Mendes, Inácio Da Silva, Virgílio Ramires, Felipe Reichert, Rafaela Martins, et al. (2018) Metabolic equivalent of task (METs) thresholds as an indicator of physical activity intensity. PLoS One 13(7): $1-10$.

14. Keytel LR, Goedecke JH, Noakes TD, Hiiloskorpi H, Laukkanen R, et al. (2008) Prediction of energy expenditure from heart rate monitoring during submaximal exercise Prediction of energy expenditure from heart rate monitoring during submaximal exercise. J Sports Sci 23(3): 289-297.

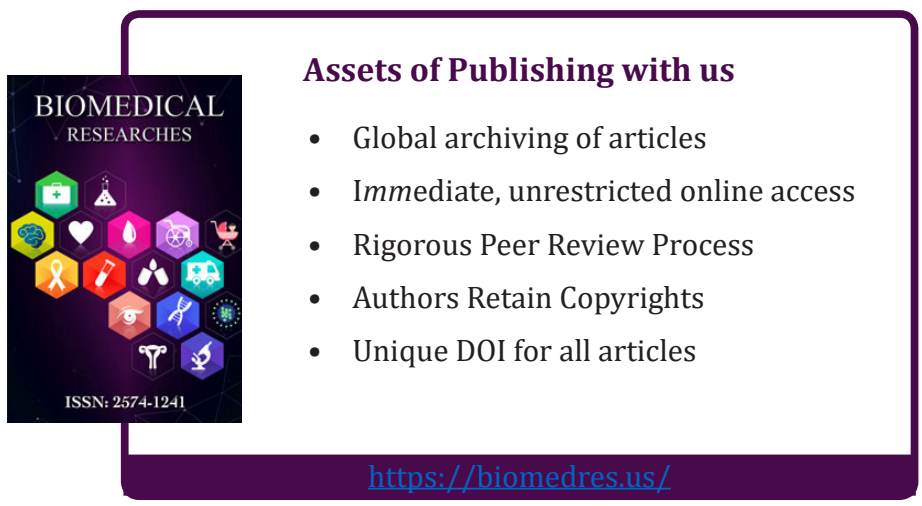

